\title{
Bioactive Compounds Obtained by Treating Dairy Wastewaters with Porphyridium purpureum ${ }^{+}$
}

\author{
Alin Vintilă 1,2, Alexandru Vlaicu 1,2, Ana-Maria Gălan 1,*, Anca Paulenco 1, Elena Radu ${ }^{1}$ \\ and Sanda Velea ${ }^{1}$ \\ 1 National Institute for Research \& Development in Chemistry and Petrochemistry - ICECHIM Bucharest, \\ 202 Spl. Independentei, 060021 Bucharest, Romania; vintila_alin_94@yahoo.com (A.V.); \\ alexvlaicu16@yahoo.co.uk (A.V.); ancapaulenco@gmail.com (A.P.); nina.radu58@yahoo.ro (E.R.); \\ sanda.velea@icechim.ro (S.V.) \\ 2 Faculty of Applied Chemistry and Materials Science, University Politehnica of Bucharest, 1-7 Polizu Street, \\ 011061 Bucharest, Romania \\ * Correspondence: anamariagalan.88@gmail.com \\ † Presented at the 16th International Symposium "Priorities of Chemistry for a Sustainable Development" \\ PRIOCHEM, Bucharest, Romania, 28-30 October 2020.
}

Published: 11 November 2020

Keywords: microalgae; wastewater treatment; bioactive compounds extraction

Annually, 11 million tons of dairy wastewaters are released into the environment worldwide. Over recent decades, cheese whey has been considered the most important pollutant of the dairy industry, associated with serious environmental hazards if sustainable treatments are not applied. As a result, several studies have been conducted in order to develop alternative methods for cheese whey valorization [1].

The purpose of this work was to study the effect of growing microalgae on dairy wastewater. The microalgae strain chosen was Porphyridium purpureum. The growth medium (specifically Artificial seawater - ASW) was prepared through the addition of salts that comprise the ASW medium in deproteinized cheese whey, used as carbon source. Experiments were carried out with samples of increasing concentrations of cheese whey, calculated as amount of lactose $(0,2.5,5,7.5,10$ $\mathrm{g} / \mathrm{L}$ )-Figure 1 . The effects of growing microalgae in cheese whey medium were observed by monitoring the growth curves, biomass productivity after 10 days of growth, and pigment concentration in the dry biomass, specifically chlorophylls and carotenoids, as well as phycobiliproteins.

Cultivation of the Porphyridium purpureum microalgae strain on dairy wastewaters-cheese whey-resulted in an increase in the production of exopolysaccharides in the growth medium, proportional to the amount of lactose present. The analysis of the growth medium shows that the microalgae consumed the lactose present almost completely, with small amounts being found in the samples of higher concentrations at the end of the cultivation process.

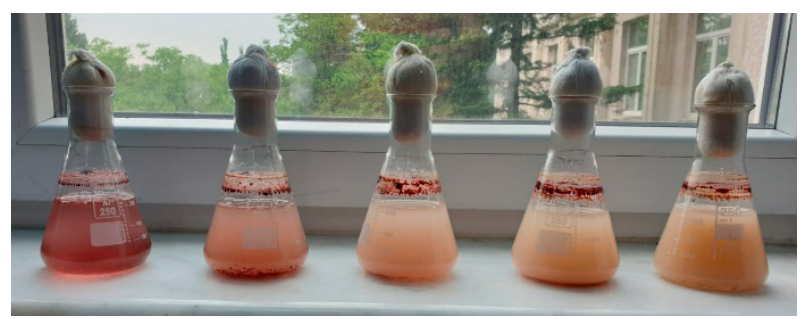

Figure 1. Cultivation of Porphyridium purpureum microalgae strain on dairy wastewaters-samples of increasing concentrations of lactose $(0,2.5,5,7.5,10 \mathrm{~g} / \mathrm{L})$. 
Continuous work will focus on the extraction, characterization, and quantification of the bioactive components present in the microalgae strain. Preliminary results suggest this is a viable route for valorization of whey present in dairy wastes, which are purified through microalgae growth.

Acknowledgments: This work was supported by PN III Program, PN-III-P1-1.2-PCCDI-2017; Program 1-Development of national CD system; Subprogram 1.2-Institutional performance, complex projects developed in CDI consortia, Contract 32PCCDI/2018 and PN 19.23.01.02.

\section{Reference}

1. Lappa, I.K.; Papadaki, A.; Kachrimanidou, V.; Terpou, A.; Koulougliotis, D.; Eriotou, E.; Kopsahelis, N. Cheese whey processing: Integrated biorefinery concepts and emerging food applications. Foods 2019, 8 , 347.

Publisher's Note: MDPI stays neutral with regard to jurisdictional claims in published maps and institutional affiliations.

(C) 2020 by the authors. Licensee MDPI, Basel, Switzerland. This article is an open access article distributed under the terms and conditions of the Creative Commons Attribution (CC BY) license (http://creativecommons.org/licenses/by/4.0/). 